\title{
Denialism as Applied Skepticism: Philosophical and Empirical Considerations
}

\author{
Forthcoming in Erkenntnis \\ MatThew H. Slater, JoAnna K. Huxster, Julia E. Bresticker, Victor LoPiccolo
}

The scientific community, we hold, often provides society with knowledge - that the HIV virus causes AIDS, that anthropogenic climate change is underway, that the MMR vaccine is safe. Some deny that we have this knowledge, however, and work to undermine it in others. It has been common (but not uncontroversial) to refer to such agents as "denialists". At first glance, then, denialism appears to be a form of skepticism. But while we know that various denialist strategies for suppressing belief are generally effective, little is known about which strategies are most effective. We see this as an important first step toward their remediation. This paper leverages the approximate comparison to various forms of philosophical skepticism to design an experimental test of the efficacy of four broad strategies of denial at suppressing belief in specific scientific claims. Our results suggest that assertive strategies are more effective at suppressing belief than questioning strategies.

\section{Denialism as a Social-Epistemic Problem}

It is well known that many people feel empowered to reject evidence and expert testimony on a great number of issues. Such denials range from the absurd and trivial (that the earth is flat) to the nuanced and dangerous (that the MMR vaccine causes autism or that the risks of climate change have been overstated). At the personal level, denial can be "active" or "passive" (Cohen 2001), recognized by the denier as at odds with the evidence or not. It can be inwardly directed (as in the case of self-deception or epistemic akrasia) or discursive, as when paid spokespeople question the science of nicotine addiction (Michaels 2008) or the connection between HIV and AIDS (Kalichman 2009). Denial can be motivated in various ways - either by material reward or recognition (Oreskes and Conway 2010a; Dunlap and McCright 2011) or more subtly by allegiance to one's ideological tribe, emotion, or values (Kahan et al. 2011; Markowitz and Shariff 2012; Norgaard 2011).

When active denial has a discursive aim (explicit or implicit), this aim can likewise vary widely. In the social epistemic context, however, a typical aim is suspension of others' belief - or suppression their confidence in that belief - on a given matter. It has been well documented that the denial of the dangers of cigarette smoke was intended primarily to forestall regulatory action by seeding doubt on the relevant science, though the science was well in hand (Michaels 2008; Oreskes 
and Conway 2010a). It has thus been common in recent decades to refer to the detractors of such consensus science as "denialists" or "contrarians" (Oreskes and Conway 2010a; Diethelm and McKee 2009; Kuhn 2012; Michaels 2008; Steffen 2011; Garvey 2008; Odenbaugh 2012).

Not surprisingly, many of these individuals (and groups) bristle at such monikers, preferring to be called "skeptics" - highlighting, presumably, their putatively positive epistemic role as counterweights to what they see as an overly dogmatic scientific community. Science enthusiasts are understandably reluctant to grant them this label, holding that the sort of "institutional skepticism" we see in science (Merton 1942) is something importantly different and positive. We see this attitude expressed in a recent paper by Lewandowski et al:: "Public debate and skepticism are essential to a functioning democracy. Indeed, skepticism has been shown to enable people to differentiate more accurately between truth and falsehood" $(2016,538)$. The "skepticism" promoted by denialists, by contrast, is seen as disingenuous or ideologically-motivated and thus a distinct phenomenon; Torcello (2016) calls it "pseudoskepticism" (compare the term 'pseudoscience').

Lewandowski et al. claim that the "dividing line between denial and skepticism" can be identified "with relative ease because denial expresses itself with considerable homogeneity" (ibid.), arguing that denialism commonly involves conspiracy theories, personal attacks, and incubation in "echo-chambers" of various sorts (538-9) and the avoidance of legitimate "scientific debate" or peer review (543). But it does not follow from the homogeneity of denialism that it is distinct from skepticism.

We do not believe that drawing a sharp distinction between denialism and skepticism is well motivated. First, the framework that treats skepticism as generally virtuous and denialism as pernicious is historically and philosophically problematic. Here we join Coady and Corry in rejecting the view that skepticism is a virtue; as they put it, "[s] kepticism about some topics is justified. Skepticism about other topics is not. Skepticism itself is neither virtuous nor vicious; it should be regarded as epistemically neutral” (2013,3). Second, we disagree with Coady and Corry in regarding these denialists, about, say, anthropogenic climate change (henceforth 'ACC') as generally aiming for disbelief in some propositions as their discursive goal. Some, doubtless, are; but as Oreskes and Conway (2010) point out, the history of organized denial campaigns offers many examples of contrarian campaigns employing "contrarian experts" to muddy the water and delay action (e.g., on regulating tobacco or mitigating acid rain). In such cases, while the agents propounding contrarian 
claims represent themselves as disbelieving (and may in fact disbelieve the claims in question), their presumptive aims are satisfied by their audience merely suspending belief. Lay observers, in a sense, say to themselves: "Well, some people say P, others say not-P; I don't know what to believe." As a strategy for disrupting public consensus formation and thus slowing democratically supported intervention, this strategy takes advantage of an epistemic asymmetry: proponents of regulation are playing for the win (belief by sufficient numbers of citizens) whereas denialists are often playing for a tie (suspension of belief).

One might see this as further reason for thinking that 'denialist' paints with too broad a brush: some alleged "denialists," after all, do not deny that ACC is occurring; they merely claim that it's too soon to tell. Nevertheless, a core unifying stance for both varieties is the denial that we know (that anyone knows) that ACC is occuring. As we discuss below, such denial comes by way of discursive strategies analogous to those of familiar philosophical skeptics. Thus we find it productive to think of denialism as a certain form of applied skepticism. It is not generally responsible or epistemicallymotivated skepticism, but it is skepticism nonetheless. It is properly called denial because (skeptical paradoxes aside) scientists do clearly know that ACC is occurring (IPCC 2014).

Seen in this light, it is surprising that philosophers - particularly those interested in social epistemology — have devoted little attention to denialism (cf. Torcello 2016). At best, this represents a missed opportunity to engage with a pressing social issue. If denialism suppresses belief from where it ought to be (given our best evidence) and if this suppressed belief causes harm, then denialism causes harm. We submit that both of these "if"-clauses are pretty clearly true in general. Concerning harm, we need only reflect on the efforts of the tobacco industry and the HIV-AIDS denialism of Thabo Mbecki's presidency in South Africa to recognize that (almost certainly) denialism has cost lives. It is poised to continue to do so in the context of climate change and the question of the safety of childhood vaccines as well (here too it probably already has).

Psychology has been on the case, accumulating both direct and indirect evidence that denial campaigns are effective at suppressing belief (see, e.g., Leiserowitz et al. 2013; McCright et al. 2016). Given what is at stake, a pressing question for researchers in science education and communication (among other fields) is how we might "inoculate" the laity from the skepticism promoted by motivated denialists (van der Linden et al. 2017). But so far, little attention has been devoted to discerning what specific denialist strategies are most effective; in the experiments of McCright et al., for example, a variety of denialist talking points and challenges were assembled together to form a 
"climate change denial counter-frame" that they found to be effective at suppressing belief in anthropogenic climate change. While this "cocktail" of challenges was found to be effective, we should not assume that each specific challenge contributed equally to the suppression of subjects' belief — indeed, some may have mitigated the effect of others owing to "boomerang" effects. Assuming that effective "inoculation" and denial-response strategies will need to be tuned to the specific denialist challenge, it would be helpful to know which strategies for belief suppression are most effective. One aim of this paper is to make progress on this goal.

Answering this question empirically requires regimenting denialist strategies in some way and experimentally testing their efficacy in belief suppression. There are many ways of doing this. One approach might simply collect a large number of verbatim talking points commonly found in various forums, conferences, blogs, books, TV appearances, and so on, and testing the most common. We opted for a more general approach — taking our cue from thinking of denialism as a form of "applied skepticism" - distinguishing strategies on the basis of the generality of their content and whether they raised questions or issued a specific challenge.

The paper is structured as follows: in the next section $(\$ 2)$, we distinguish between a few basic varieties of denialist challenge and compare them to different traditions of skepticism. In $\$ 3$, we describe two empirical studies that explore the efficacy of different styles of denialist challenge for

suppressing belief. Our results suggest that a disagreement-oriented skeptical model is more effective; $\$ 4$ offers a general discussion and suggests some next steps for further research.

\section{Varieties of Denialist Strategies}

Let us now consider some more specific comparisons between denialist strategies and certain forms of skepticism. We begin with the most familiar: Cartesian skepticism. The Cartesian skeptic asks an apparently simple question: Can you be sure that you're not dreaming right now? Or possibly: Might you not be in the Matrix? Do you, in general, have any way of ruling out the possibility that you are massively deceived right now? Such questions, of course, are supposed by the skeptic to lack good, non-question-begging answers. And if you cannot rule out that the proffered skeptical scenario is true - even if it seems absurdly unlikely — then you cannot rightly claim to know anything that such a massive deception would undermine. Something similar is apparently going on when climate change or AIDS contrarians pointedly ask whether you can be sure that everything you think you 
know about climate change or the HIV-AIDS link isn't in fact misinformation spread by a powerful conspiracy. Most of us have little direct, first-person acquaintance with the relevant evidence; we are almost entirely dependent on the say so of third parties (Lipton 1998; Keren 2007; Anderson 2011). But if we cannot answer this general question about our ability to rule out the possibility of others' error or dishonesty, then how can we claim to know — and shouldn't we reduce our confidence in — the propositions we claim to know?

Notice that in this case, the skeptic need not actually assert that the skeptical scenario - the conspiracy, massive error, or whatever it is - actually is the case. They merely need to raise the possibility in a way that makes it salient. To many, simply opening the question suffices to achieve the skeptical outcome. This can be observed in a philosophically and scientifically ham-fisted (yet often apparently effective) way in the context of public debate over matters that are acknowledged to admit of a certain level of uncertainty. Oreskes and Conway point out in an editorial in Nature (2010b) that scientists are often overcareful about acknowledging uncertainties and caveats, “outlining what they don't know before proceeding to what they do - a classic example of what journalists call 'burying the lead'” (687). Having granted some possibility that a scientific proposition might be wrong, some are erroneously inclined to think of the situation as an even-odds guess.

Cartesians can press conspiracy theories progressively further, for example by pointing to purported facts that seem anomalous or in conflict with some "official story" as suggestive that a conspiracy is afoot. The "Climategate" incident - that is, the theft and selective quoting of private emails of climate scientists - offered a particularly rich opportunity for casting doubt on the trustworthiness of climate scientists in general. By quoting out of context correspondence between scientists that seemed nefarious to the laity, e.g., concerning the "manipulation of data" (a phrase that can sound sinister out of context), climate change denialists were able to raise to salience the possibility of a massive, organized deception without presenting any evidence that there was such a thing. The question then becomes how can we be sure that there's not a massive conspiracy of scientists? Don't we need to verify that there is not before we can accept anything they have to say? This can develop into full-fledged assertions that the conspiracy theory or skeptical scenario in question is in fact the case. Many well-known denialists of course take this route.

Just as Cartesian skeptics call into question the general reliability of our belief-forming mechanisms, science skeptics might likewise cast doubt on a scientific claim by asserting that science is unable to marshall sufficient evidence or be sufficiently objective to speak reliably on a given topic. 
One can do this by claiming that the specific evidence is by its nature unreliable (or cannot be trusted) or by claiming that the evidence does not exist or is incompatible with other more trustworthy or probative facts. We might think of these cases as involving very general challenges either by raising pointed questions or making stronger assertions concerning the possibility of general scenarios that would tell against a large body of claims at once.

We can contrast this broadly Cartesian strategy with an approach adopted by some Pyrrhonian skeptics. While Pyrrho (via Sextus Empiricus) offered some general, transcendental arguments for skepticism, one of the Pyrrhonian's go-to techniques was to raise specific challenges. Fogelin puts the contrast between the general and specific strategies nicely:

At first glance, Pyrrhonian skepticism may, indeed, seem mild in comparison with various forms of Cartesian skepticism. There is something exhilarating, almost giddy, in the thought that all of our common beliefs about the world might just be false, and Cartesian skeptical scenarios seem to raise just this possibility in a vivid form.... [I]t does not take radical — globally dislocating — scenarios to introduce suspension of belief. It is quite sufficient to note - and dwell on - the fact that our empirical claims are made in the face of unchecked, though checkable, defeators... Given any empirical assertion, it is always possible — indeed always easy — to point to some uneliminated (though eliminable) possibility that can defeat this claim. Nothing like brains in vats are needed to achieve this purpose. (Fogelin 1994, 192-193)

Let us thus consider this aspect of Pyrrhonian skepticism as emblematic of a specific approach to offering a skeptical challenge (in contrast with the more general Cartesian approach). As before, we can think of such challenges as proceeding dialectically either via questions or assertions. For example, leaving the restaurant, you say that your car is parked on 3rd Street - indeed, you know that it's parked there. The skeptic challenges: Are you sure? Do you know, for instance, that it has not been stolen in the past five minutes? This question works in the same way as the Cartesian's question when it comes to this particular knowledge claim; you probably cannot rule this possibility out and so may fail to feel satisfied that you do know where your car is parked. But the Pyrrhonian has a dialectical advantage over the Cartesian here owing to the tradeoff of generality for specificity: the possibility itself may seem quite a bit more credible. Car theft, after all, is something that occurs.

A Pyrrhonian employs corresponding assertions when they draw on the skeptical modes from disagreement (Sextus Empiricus 2000, 40-41). If my epistemic peer offers me an argument pointing to a conclusion at odds with my belief — if the considerations are indeed "equipoised" — then it seems that I ought to suspend belief. This simple idea has been much discussed in recent years under 
the rubric of the epistemology of disagreement. In his now classic paper, Christensen offered a case that many of us can easily relate to:

Suppose that five of us go out to dinner. It's time to pay the check, so the question we're interested in is how much we each owe. We can all see the bill total clearly, we all agree to give a 20 percent tip, and we further agree to split the whole cost evenly, not worrying over who asked for imported water, or skipped dessert, or drank more of the wine. I do the math in my head and become highly confident that our shares are $\$ 43$ each. Meanwhile, my friend does the math in her head and becomes highly confident that our shares are $\$ 45$ each. How should I react, upon learning of her belief?

I think that if we set the case up right, the answer is obvious... I should lower my confidence that my share is $\$ 43$ and raise my confidence that it's $\$ 45$. In fact, I think (though this is perhaps less obvious) that I should now accord these two hypotheses roughly equal credence. (Christensen 2007, 193)

In Christensen's case, it's important that we recognize the disagreeing party as our epistemic peer.

We would probably not feel compelled to suspend our belief (or even decrease our confidence) if the disagreement was with an eight year old or our friend who is notoriously bad at math.

Note also the first-person character of the case. Many instances of denialism, however, will be second-person - for example, when an assertion of one apparent authority is countered by a denial from another. The shift from a first-person to second-person context may actually heighten the skeptical impact of this disagreement. A neutral observer of this disagreement may not be well positioned to determine who is a relevant epistemic authority and who is not. Doing so can be difficult enough in non-contentious contexts, but is especially fraught when efforts are taken to artificially build the apparent credibility of one testifier and reduce that of the other (Almassi 2012; Collins and Evans 2007; Goldman 2001). Thus a sort of second-order skepticism can take hold: if I must suspend belief about whether the disagreeing parties are epistemic peers, then I may not be able to rule out their disagreement as epistemically significant — for all I know, it is, and I should suspend my belief.

A second consequence of the disagreement's being second-person is that the neutral party often will not be in possession of information that might resolve the disagreement. In the check-splitting case, the grounds for my answer are introspectively available to me; in certain circumstances, this may encourage steadfastness (Kelly 2010; Lackey 2010). Merely observing the conflict, however, I will generally be deprived of such immediate opportunities to evaluate the grounds for either 
position. These effects can also interact: when an apparent expert challenges a generally acknowledged expert by raising a very specific or technical point - which neutral observers may be unable to follow - it may also suggest to the observers that the challenger is a well-informed, epistemic peer of the acknowledged expert.

Worse yet, few of us are actually neutral. When asked to determine whether some person with a certain range of qualifications is a "knowledgeable and trustworthy expert," our answers will often be guided mainly by whether their views fit with our cultural outlooks (Kahan et al. 2011, 167; Kahan 2014; Ahola 2016). Denialists adopting this strategy thus both rely on motivated cognition while simultaneously facilitating its operation by offering skeptics of consensus science a plausible justification for why they ought to suspend their belief.

We could doubtless make other comparisons, but as a start, let us regiment our denialist strategies as varying along two parameters: form (question vs. assertion) and content generality (specific or general). These yield four general strategies that loosely correspond to the discursive skeptical strategies discussed above. One reason for regimenting strategies this way is the possibility of a fruitful interaction with anti-skeptical strategies explored in the philosophical context. For example, one might adopt a sort of Moorean response to the denialist who raises very general questions about the reliability of science as a method for making contact with the world (1925/1993, 1939/1993); or one might employ Austin's ordinary language approach to the specific question strategy (1946/1979).

Consider the latter for a moment as an example. Suppose that John makes a specific claim to knowledge - that there's a goldfinch in the garden, say. You ask him pointedly "Are you sure it's not a goldcrest?" Austin points out that there are a number of specific questions you may have in mind; more importantly, he argues that there had better be something behind your question if John is to take it seriously. If John answers that he knows from the markings and you persist by saying "Are you sure that another bird doesn't have those same markings?" or "That's not enough," Austin thinks that something untoward is potentially going on: "you must have in mind some more or less definite lack. 'To be a goldfinch, besides having a red head it must also have the characteristic eyemarkings' [and so on].... If there is no definite lack which you are at least prepared to specify on being pressed, then it's silly (outrageous) just to go on saying 'That's not enough'” (1946/1979, 84). This point can be neatly connected to Torcello's (2016) contention that denialism is "pseudoskepticism" in light of its unwholesome motivations (in contrast to those adopting a general 
methodological skepticism familiar in science or expressing rationally well-founded doubts). The common thread here is that certain skeptical challenges are legitimately rebuffed or ignored on the basis of their origin (if, for example, they are disingenuous or better characterized as expressions of ideology rather than reflections of the evidence).

This is not meant as a defense of Austin's normative point. But assuming that it is sound, it suggests an avenue of response to denialists who adopt a certain genre of skeptical strategies. There would still remain a psychological question of whether the proffered response would be generally effective in turning away a denialist challenge. But before researchers address this question, it is worth knowing which of the four broad classes of skeptical strategies are psychologically more effective at instilling doubt. As noted above, researchers already have evidence that denialism is generally effective, but what kind of denialist challenges deserve our attention as the most effective is so far unclear. Thus we turn to two empirical studies we conducted to answer this question. These results inform ongoing work determining whether it is possible to inoculate targets of denialism against the untoward suppression of their beliefs.

\section{The Studies}

Here is a more precise statement of our initial research question (discussed in $\$ 3.1$ ): given the communication of a relatively simple scientific idea, which of our four-fold content-form typology of denialist challenges (general assertion, general question, specific assertion, specific question) are most effective at suppressing subjects' acceptance of the communicated idea? Of course, there are a number of further dimensions we could have considered (in addition to form and content). Anderson et al. (2014), for example, studied the effect of "tone" in online communication fora. One could also examine a more subject-specific regimentation, identifying certain patterns or talking points that are familiar in the context of a particular subject (such as climate change or vaccine safety). These may be worth exploring and the methodology we describe is easily adapted to other approaches. Our second research question (discussed in $\$ 3.2$ ) is whether skeptical challenges exhibit a "dose-response" effect — that is, do more challenges lead to greater suppressions of belief?

In this set of studies, we chose a subject matter paralleling cases where denialist efforts have been prominent - in three senses: (1) an issue on which science is primarily relevant and needed (as opposed to, say, a question of policy); (2) for which a strong scientific consensus has emerged; and 
(3) a matter that concerns risk. However, we also sought to investigate a case that would differ from prominent targets of denialists in being (so far) relatively non-politically- or ideologically-entangled and about which many people are largely ignorant. Preliminary testing indicated that the risks of the Zika virus would fit this profile. This topic is not apparently ideologically entangled (a finding confirmed by our results), but has suffered from some misunderstanding in the public — in particular, confusion about the ways in which the virus is spread, the link between Zika and the birth defect Microcephaly, and the severity of the disease for those who contract it have been documented (HORP 2016).

\subsection{Four Modes of Denialist Challenge (Study 1)}

\section{$\underline{\text { Methods }}$}

\section{Participants}

Study 1 employed a sample of 800 participants from the American population with a completion rate of 94 percent (final sample size $n=758$ ). The embedded experiment was conducted online using Qualtrics survey software and the sample was collected using Amazon Mechanical Turk in February and March of 2017. Participants were compensated 50 cents for completion of the survey. All results were analyzed using SPSS.

\section{Experimental Design}

Participants were asked to take part in a study on the communication of scientific theories. The between subjects experiment began with a short expository paragraph detailing the leading theory concerning transmission and risks of the Zika virus (see online Supporting Material). After reading the expository paragraph, participants were asked to rate their degree of belief in three statements related to the description of the theory. Belief ratings ranged from zero (completely disagree) to 100 (completely agree). The belief statements were as follows:

1. The Zika virus can be spread through sexual transmission.

2. The greatest risk from the Zika virus is to pregnant women and their babies.

3. Microcephaly is a condition in which a baby's head is much smaller than expected. 
Participants were then randomly assigned either a denialist challenge from one of four challenge categories, or a control statement. Participants in the control group were told "The Zika virus theory presented to you was printed in a popular science magazine" and then moved on with the survey. The participants from each of the denialist challenge groups read the statement: "The Zika virus theory presented to you was printed in a popular science magazine. The article generated many responses, including the following:" In this way, the challenges were presented as public comments to the Zika theory piece. The four challenge categories were designed to test the effects of content (general or specific) and form (question or assertion) (Table 1). All participants were then retested on the same three belief statements, again selecting a belief rating between 0 and 100 .

Table 1: Denialist challenges used in Study 1.

\section{Form}

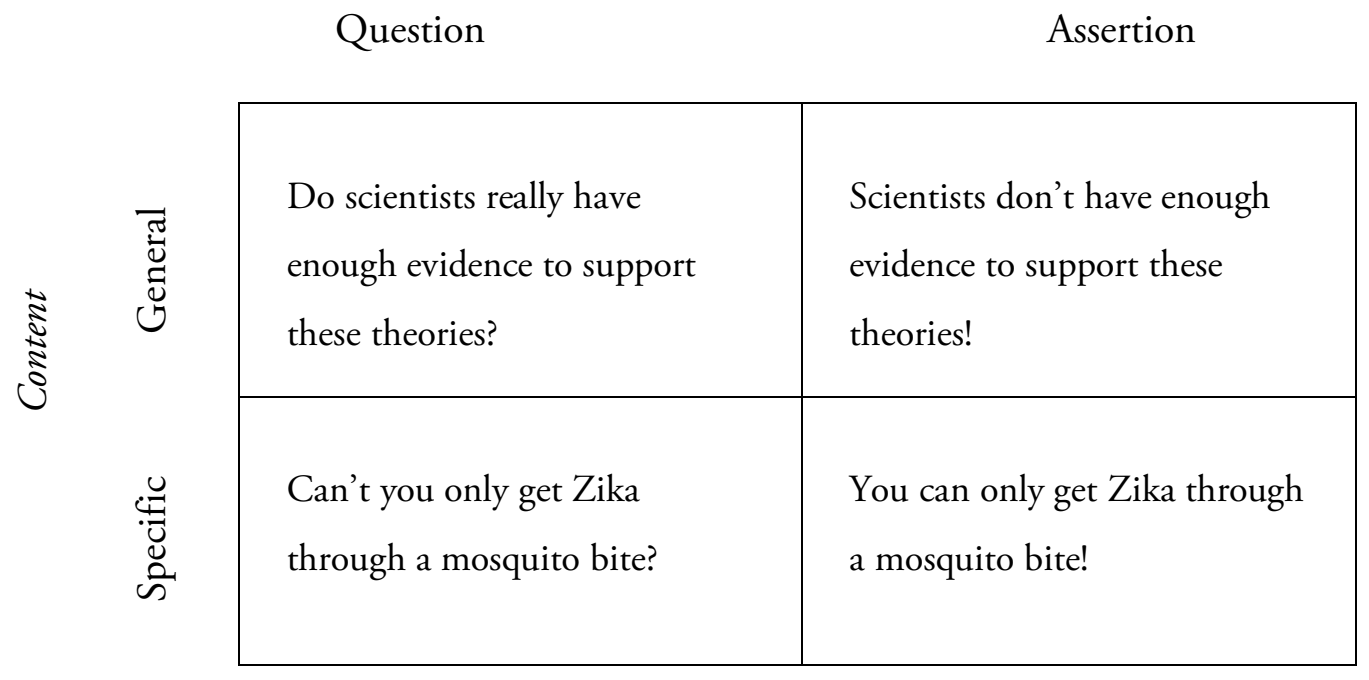

After completion of the embedded experiment, participants were debriefed and offered the option to exclude their results from the study. This exclusion, and that of participants who did not fully complete the study, resulted in a final sample size of $\mathrm{n}=758$.

\section{Measurement}

The effectiveness of the denialist challenge statements was determined by the overall change in total belief scores. Participants scores on the three belief statements were totaled to create a pre-beliefscore 
out of 300, and a post-belief score out of 300. The difference between these scores (post-belief minus pre-belief) was the dependent variable of belief change. Therefore, a negative difference between prechallenge total belief score and post-challenge total belief score would constitute an effective denialist challenge. The more negative a belief change score, the more a participant's belief lowered between measurements.

Demographic variables included were Age $(\mathrm{M}=37, \mathrm{SD}=12.3$, Range $=18-75)$, gender $(50.3 \%$ female), level of education ( $49.5 \%$ with bachelor's degree or higher), income $(\mathrm{M}=\$ 50,000)$, race (83.2\% white), and political party affiliation ( $42 \%$ democrat). The results of all demographic measurements can be seen in the Supporting Material. In addition to these demographics, participants were asked to respond to two value predispositions. Religiosity was measured by asking "How important is religion in your life?" Responses were recorded on a 5 point scale with 1 = "Not at all important" and $5=$ "Extremely important" $(\mathrm{M}=2.36, \mathrm{SD}=1.49)$. Trust in science was measured by asking "How much would you say you trust in the findings of science?" with 1 = "Not at all" and $5=$ "A great deal" $(\mathrm{M}=4.11, \mathrm{SD}=.855)$. We included religiosity and political ideology to confirm that we had, in fact, chosen a subject (Zika) that was not significantly tied to religious or political ideologies. Trust in science and religiosity are frequently negatively correlated (Nadelson and Hardy 2015, Cacciatore et al 2016), and we were also interested in the ways these variables might interact with belief change. We predicted that those with high trust in science would have high prebelief scores, and would be less likely to lower their belief.

\section{$\underline{\text { Results and Analysis }}$}

A one-way between subjects ANOVA for belief change (post-belief minus pre-belief) showed a significant difference between the five treatment groups $\mathrm{F}(4,753)=10.26, p<.001$. Mean belief change for each of the treatment groups can be seen in Figure 1, below. Post hoc analysis using Tukey's HSD" indicated that the "Specific Assertion" condition $(\mathrm{M}=-10.20, \mathrm{SD}=25.03)$ and the "General Assertion" condition $(\mathrm{M}=-13.44, \mathrm{SD}=40.58)$ both produced significantly more change in belief than the control $(M=3.91, S D=21.99)$. Neither the "Specific Question" condition $(M=-1.69$, $\mathrm{SD}=23.84)$ nor the "General Question" condition $(\mathrm{M}=-1.54, \mathrm{SD}=19.16)$ were significantly

\footnotetext{
${ }^{1}$ Tukey's HSD was chosen as the appropriate post-hoc test because the sample sizes are close to equal with similar variances and Tukey has good power and control over Type 1 error.
} 
different from the control. Those in the "Specific Assertion" condition were also shown to have a significantly greater change of belief than those in the "General Question" condition, and the "General Assertion" condition participants had a significantly greater change in belief than those in the both the "General Question" and "Specific Question" conditions. In Figure 1 you can also see that those in the control condition showed an increase in belief. This is expected as an exposureeffect, as subjects saw the same group of belief questions twice.

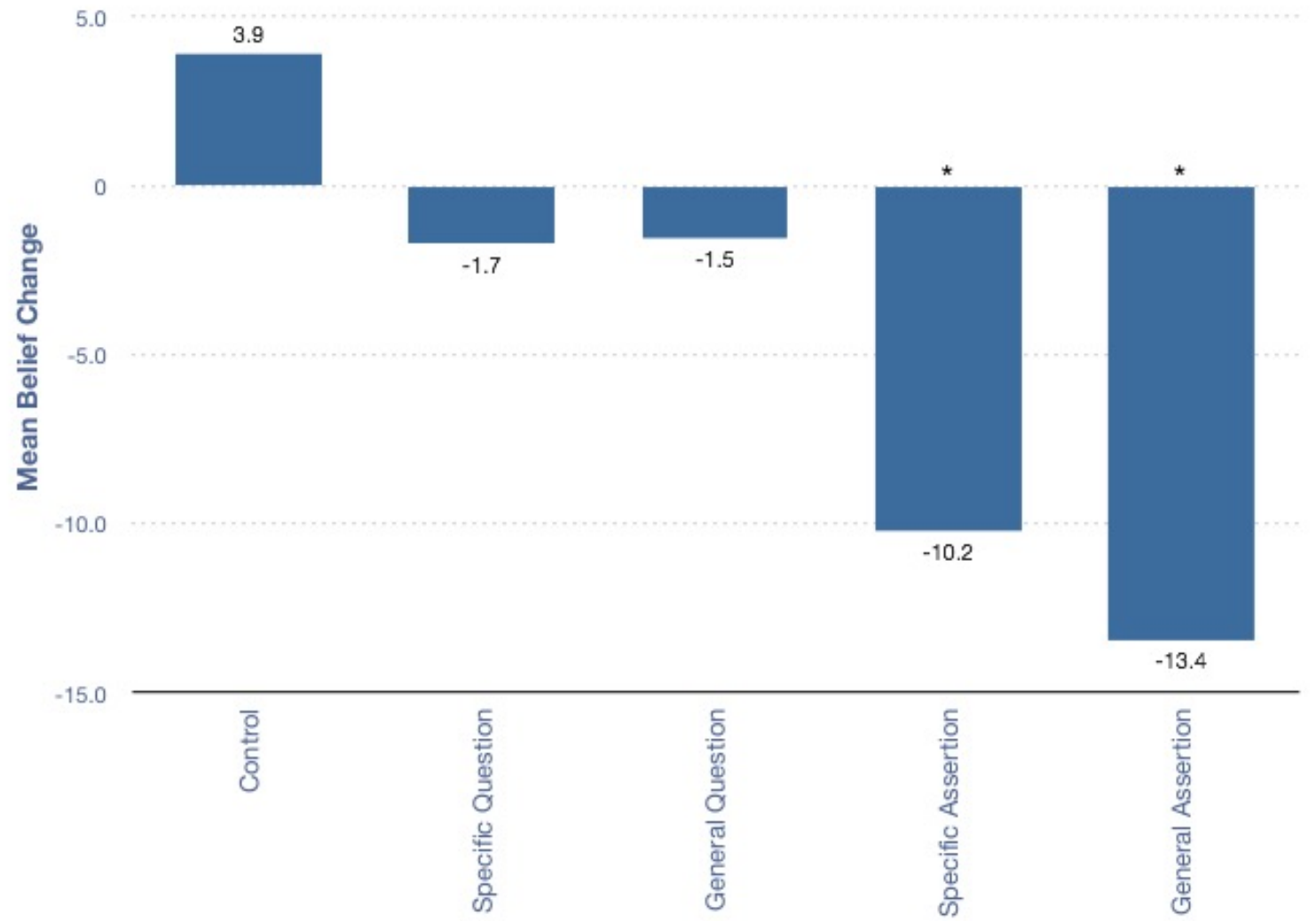

Figure 1: Mean Belief Change for Treatment Groups in Study 1; * significance at $\mathrm{p}<.001$ level.

To more explicitly test the effects of form versus content, we conducted a two-way ANOVA for the effects of content ("general" vs. "specific" denialist prompts) and form ("question" vs. "assertion" denialist prompts) on belief change. There was no statistically significant interaction between the effects of content and form on belief change, $F(1,753)=.586, p=.444$, and no significant difference in belief change for the content groups $(p=.484)$. There was, however, a significant difference in belief change between form groups $(p<.001)$. 
A one-way between subjects ANOVA comparing belief change between all those participants receiving a "general" denialist prompt, all participants receiving a "specific" denialist prompt, and the control group revealed a significant difference between groups $\mathrm{F}(2,755)=9.32, p<.001$. Post hoc analysis with Tukey's HSD (see note 1$)$ showed that both "specific" $(\mathrm{M}=-5.94, \mathrm{SD}=24.77)$ and "general" $(\mathrm{M}=-7.53, \mathrm{SD}=32.30)$ prompt groups changed their belief significantly compared to the control group. Both types of content were, therefore, similarly effective.

In contrast, post-hoc analysis of the significant one-way between subjects ANOVA comparing belief change between the "question," "assertion," and control groups $(\mathrm{F}(2,755)=20.03, p<.001)$ revealed that only the "assertion" group $(\mathrm{M}=-11.83, \mathrm{SD}=33.75)$ was significantly different from the control, while the "question" group $(\mathrm{M}=-1.62, \mathrm{SD}=21.59)$ was not.

For all participants receiving denialist prompts, no significant correlations were found between belief change and religiosity, and no significant differences were found for political party affiliation. A significant relationship was found between trust in science and pre-belief, $\mathrm{r}=.279$, and belief change, $\mathrm{r}$ $=.159$, (both $p s<.001$ ), indicating that participants with higher trust in science had a higher prebelief, and were less likely to change their beliefs in the face of denialist challenges.

\section{$\underline{\text { Discussion }}$}

The correlation between trust in science, pre-belief, and belief change indicate that, as expected, the more trust one has in science, the more inclined they are (though obviously not perfectly so) to accept messages presented as scientific conclusions and to retain these beliefs in the face of denialist challenge. The results of Study 1 indicate that denialist prompts worded as assertions rather than as questions are more effective at lowering belief in a non-ideologically entangled scientific claim. Although the general and specific assertions targeted different aspects of the given theory, they were still more effective at lowering belief than the specific and general questions. Statistical analysis of the difference in mean belief change between treatment groups, and those examining the differences in forms versus the effects of content support lead to a consistent finding. At least in the case of the Zika virus, form has a much more important influence on the effectiveness of denialist claims than the specificity (or lack thereof) of the content. This suggests that whether denialists formulate their skeptical challenges in grand, Cartesian generalities or Pyrrhonian specifics, they are well-advised to do so in the stronger, assertive forms. Skeptical efficacy thus seems to cut across skeptical traditions (at least as we rudimentarily regimented them). 


\subsection{Dose-Response and Interaction Effects (Study 2)}

Our second study built on the results of Study 1 by focusing on the assertion challenges (we dropped the question challenges). Our aims in this study were to (a) replicate our initial observation that counter-assertion was effective in suppressing belief in large demographically-representative sample, and (b) determine whether this suppression exhibited a dose-response effect.

\section{$\underline{\text { Methods }}$}

\section{Participants}

Study 2 employed a nationally-representative sample of 1802 participants from the American population (collected by Research Now in March of 2017) with a completion rate of 83 percent. The embedded experiment was conducted online using Qualtrics survey software and participants were compensated $\$ 2.50$ in e-rewards currency.

\section{Experimental Design}

As in Study 1, participants were asked to take part in a study on the communication of scientific theories. The between subjects experiment began with the same short expository paragraph detailing the leading theories of the Zika virus (see the online Supporting Material). After reading the expository paragraph, participants were asked to rate their degree of belief in the same three statements used in Study 1, with ratings again ranging from zero (completely disagree) to 100 (completely agree). Study 2 participants were then randomly assigned either one denialist challenge, three denialist challenges, or a control statement.

Given the results of Study 1, three specific assertions and three general assertions were used as challenges in Study 2 (Table 2). The specific assertions included the one used in Study 1, as well as two designed to target common misconceptions about Zika (HORP 2016). The general statements included the same general assertion used in Study 1, and two general statements that could be applied to any scientific theory about which members of the public might perceive risk.

Participants receiving one challenge (Dose 1 group) were randomly assigned one of the six challenges. Participants receiving three challenges (Dose 3 group) were assigned a random combination of 3. All possible combinations of challenges yielded 20 "treatment sets" (as we shall call them) and one control group (all Dose 3 treatment sets can be seen in Figure 3). The challenges 
were again presented as public comments to the Zika theory piece, which the all participants were told had appeared in a popular science magazine. All participants were then retested on the same three belief statements, again selecting a belief rating between 0 and 100 .

Table 2: Denialist Challenges for Study 2

\begin{tabular}{|l|l|}
\cline { 2 - 3 } Specific & $\begin{array}{l}\text { S1. You can only get Zika through a mosquito bite! } \\
\text { S2. Zika symptoms aren't mild at all; they're life-threatening! } \\
\text { S3. There's no link between Microcephaly and Zika! }\end{array}$ \\
General & G1. There isn't enough evidence to support this theory! \\
G2. Alarmists are exaggerating this so-called "problem"! \\
G3. There's no scientific consensus about this theory!
\end{tabular}

\section{Measurement}

The effectiveness of the denialist challenge statements was determined by the overall change in total belief scores in the same way as was calculated in Study 1. Participants scores on the three belief statements were totaled to create a pre-belief score out of 300, and a post-belief score out of 300 . The difference between these scores (post-belief minus pre-belief) was the dependent variable of belief change.

Demographic variables included were Age $(\mathrm{M}=50.64, \mathrm{SD}=14.55$, Range $=19-94)$, gender (57.3\% female), level of education (51.6\% with bachelor's degree or higher), income $(M=\$ 60,000)$, race $(87.4 \%$ white), and political party affiliation (34.2\% democrat). The results of all demographic measurements can be seen in the Supporting Material. The two value predispositions, Religiosity (M $=3.03, \mathrm{SD}=1.45)$ and trust in science $(\mathrm{M}=4.02, \mathrm{SD}=.865)$, were measured with the same variables as Study 1. 


\section{$\underline{\text { Results and Analysis }}$}

A one-way between subjects ANOVA for belief change showed a significant difference between the three Dose groups (i.e., between Control, Dose 1, and Does 3): $\mathrm{F}(2,1799)=8.18, p<.001$. Post hoc analysis with Hochberg's GT2 revealed that those participants in the Dose 3 group $(M=-11.44$ SD $=43.48)$ lowered their belief significantly more than those in the Dose 1 group $(\mathrm{M}=-6.39 \mathrm{SD}=$ 43.48) and those in the control group $(\mathrm{M}=.3152 \mathrm{SD}=31.49)$ (Figure 2).

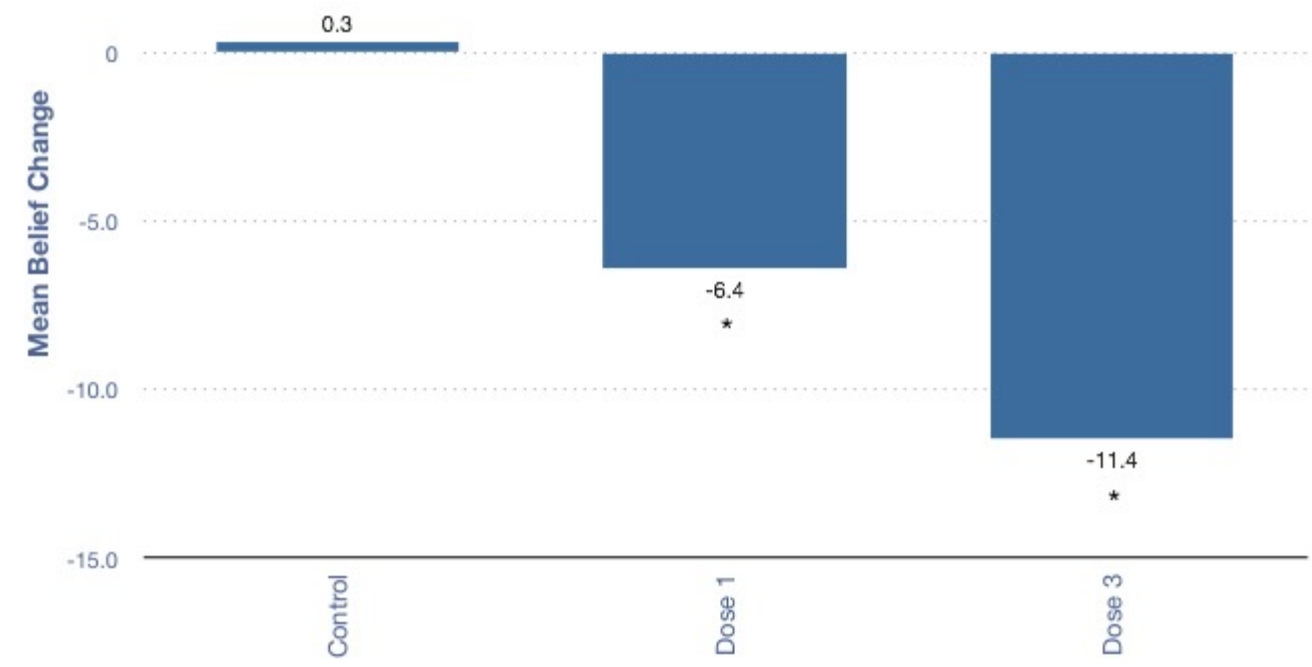

Figure 2: Mean Belief Change across Dose Groups in Study 2. ${ }^{*}=$ significance at the $\mathrm{p}<.001$ level.

Beyond the three Dose groups, we sought to identify which particular denialist statements, or sets of denialist statements, were most effective at lowering belief. A one-way between subjects ANOVA for belief change showed a significant difference between the 20 Sets and one control. Post hoc analyses with Hochberg's GT2² showed that only one of the Dose 3 treatment sets (S3,G1,G3) significantly lowered belief compared to the control (See Table 3 and Figure 3). Given the difference in sample sizes between the Dose 1 Sets and the Dose 3 Sets, separate ANOVAs (both significant) for belief change were run for all Dose 1 sets together $(\mathrm{F}(6,996)=5.49, p<.001)$ and all Dose 3 sets

\footnotetext{
${ }^{2}$ The design of Study 2 included multiple levels of sorting that rendered some sample sizes unequal. Hockberg's GT2 was the appropriate post hoc analysis in this case given the differences in sample sizes between the control group and the Dose 1 and Dose 3 sets.
} 
together $(\mathrm{F}(20,962)=2.31, p<.001)$. Post hoc analyses were performed for each ANOVA using Gabriel's PCT, as the sample sizes within each Dose treatment were only slightly unequal. Table 3 in the supplemental material shows the means and standard deviations of all of the sets. Figure 3 below shows the means for all sets, with significance level (as compared to the control) is indicated with asterisks. In these analyses, Statement 1 from the Dose 1 Set significantly lowered belief compared to the control.

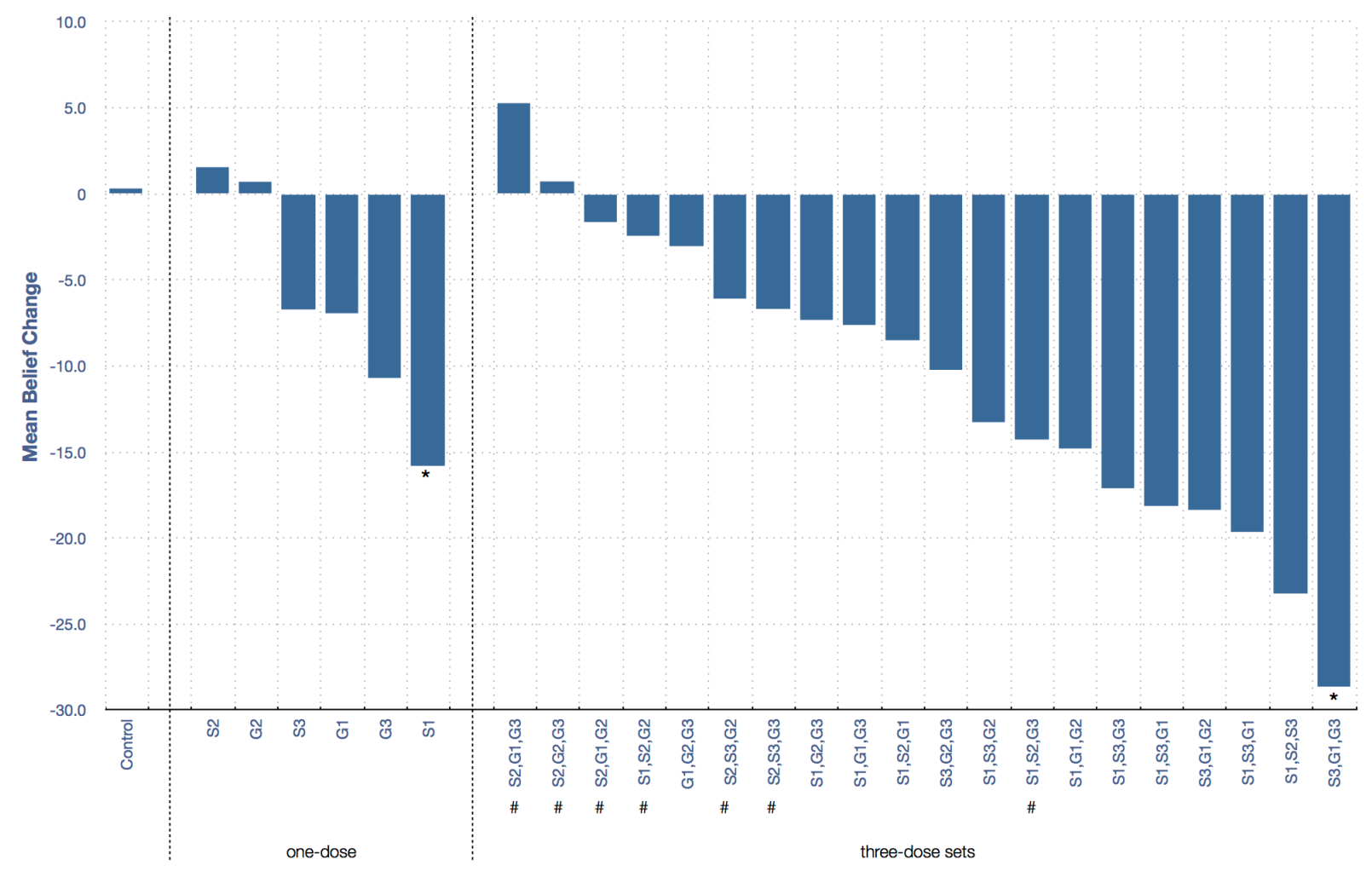

Figure 3: Mean Belief Change detail (Study 2); ${ }^{*}=$ significance at the $\mathrm{p}<.001$ level; $\#$ = conflicting dose sets.

For those participants who received denialist challenges, belief change was slightly related to religiosity, $r=-.049, p<.05$ (this negative correlation indicates that as religiosity goes up, people are more likely to lower belief) and more strongly related to trust in science, $r=.091, p<.001$ (as trust in science increases, people are less likely to lower belief). Trust in science is also significantly related to pre-belief, $r=.324, p<.001$. Again no significant differences were found for political party affiliation. 


\section{$\underline{\text { Discussion }}$}

The initial results of Study 2 comparing the Dose 1 condition and the Dose 3 condition support the idea of a "dose-effect," in which increasing the number of denialist challenges to which a participant is exposed causes them to further lower their belief. This is not, in itself, very surprising. However, it is notable that not every trio of challenges resulted in a suppression of belief. Indeed, only one of the three-dose sets led to a statistically-significant drop compared to Control. The non-significant changes may be explained, in part, by the fact that some of the sets contained statements that were in some tension with one another: two of the general statements, G2 and G3, could be seen as opposed to S2. As shown in Figure 3 (observe dose sets marked with '\#'), these sets barely lowered or even raised belief (and the effect was not statistically significant; see Supporting Material for precise values and standard deviations). One potential exception to this trend is the set S1,S2,G3 (though the effect was still not statistically significant), but the overall pattern seems to be that consistency matters in reducing layperson confidence; we return to this matter in the conclusion.

One specific statement in Study 2 was more effective compared to the others in the single-dose group (S1: "You can only get Zika through a mosquito bite!"). One possible explanation for S1's relative effectiveness is that it plays into the most common misconception held by the public about Zika (HORP 2016). Yet (internal conflicts aside), S1 does not seem to drive any obvious pattern in the multiple-dose sets. As mentioned above, one combination of statements (S3,G1,G3) was statistically-significantly effective at suppressing belief. It remains unclear what exactly about this combination subjects found so compelling.

In this larger sample size, participants were slightly more likely to lower belief if they indicated that religion was more important to them. This relationship was small but significant. As in Study 1, as participants' trust in science increased, they were less likely to lower belief in response to denialist claims.

\section{Conclusion \& Next Steps}

To summarize, we've found that — at least for the present case — denialist strategies were notably more effective when they worked in the mode of disagreement as opposed to questioning the grounds of subjects' beliefs. One can imagine several explanations for this observation. Here is one: Perhaps simply raising a question about one's facts (or about the reliability of one's sources or belief-forming 
methods) without explanation fails to motivate the possibility that one's facts might really be wrong (or unreliable), absent specific reason for thinking that there's a problem. This resonates with Austin's general anti-skeptical approach: you might question my facts or credentials, but unless you have in mind "some specific lack" such questioning often seems to fall flat. Compare two versions of Christensen's dinner check-splitting example: in the original version, when your friend arrives at a different conclusion than you do it seems quite natural to suspend (or lower) your belief that you are correct; but if your friend merely asked you "Are you sure that it's that much?" it seems both normatively and psychologically plausible that you should (or may) remain steadfast. You might reply "Yes, I just did the math. Do you have some reason for thinking I'm wrong?" Suppose now that your friend replies "Well, yes: I just did the math too and got an answer \$5 lower." This arguably changes the dynamic (though it might not always change our response). When your friend asserts a different answer, they essentially provide the sought-after grounds for their question.

Whereas Study 1 suggests that denialist challenges that had the form of assertions were more effective in suppressing belief than the question equivalents - more than any differences in the generality of a challenge's content - Study 2 shows that (at least in the present context) content matters. While we do see a dose-response effect for one combination of challenges (and overall), this was not true for each trio of challenges. This is consistent with the results of McCright et al. (2016) in which a number of distinct denials at various levels of specificity were woven together into an allpurpose ACC “counter-frame”. But simply increasing the number of challenges did not reliably decrease the belief suppression.

Not all patterns in these data are readily explained, but the hypothesis floated above - that perceived tensions within the three-dose sets of challenges reduced their efficacy — goes some ways to explain why more denial didn't generally lead to more skepticism. Again, we can imagine versions of our check-splitting scenario that illustrate the psychological plausibility of both of these effects. Four people set out to calculate the correct share of the dinner check. Your confidence wavers when you learn that one of your friends has arrived at a different number; it might drop significantly (if you're like us) when you learn that all three check-computers agree on the correct value - especially if they've arrived at it independently. Alternatively, imagine that while your friends disagree with you about the correct value, they also disagree with each other. Now, perhaps, it's not as clear what the proper response is. It seems plausible to us that the drop in confidence should not be quite as 
pronounced. Remaining steadfast in one's own calculation seems psychologically more tenable in this case than it is in the previous.

In the context of denialist challenges to consensus science, we can imagine a number of different ways in which tensions/inconsistencies might manifest: (synchronic-individual) on the same occasion by the same person; (diachronic-individual) on different occasions by the same person; (synchronic-group) on the same occasion (roughly) by different people; (diachronic-group) on different occasions by different people. Presumably cases like (synchronic-individual) will tend to have an undermining effect on the undermining power of the such challenges. It's not as obvious that (diachronic-individual) would - or should. The details should matter. People change their minds responsibly in some cases. Does this look like such a case or is it more plausibly a forced retreat to a different position consistent with a predetermined position they will defend come what may (as in ACC-denialists who shift from denying warming to denying the human-causation claim to denying that ACC is bad at all)? Similar complexities apply in the last two cases as well. It is an open question what considerations influence the efficacy of denialist strategies and why. Is it typical for members of the lay public to employ the sort of inference-to-the-best-explanation approach Lipton (1998) suggests we often use in evaluating testimony generally? To what extent do cognitive biases mitigate (or accentuate) the otherwise compromising effect of inconsistency?

Returning to the big picture, our studies suggest that research into strategies for forestalling denialism's effects ought to focus in the first instance on the more "disagreement-oriented" analysis of denialism. Are there ways in which members of the public can be "inoculated" from this form of denial in initial communication and education efforts? Are there ways in which the skeptical effects of counter-messaging can be reversed after the fact - e.g., by getting subjects to recognize countermessaging that is motivated by ideology or material gain (Christensen 2014), perhaps by pointing out suspicious inconsistencies or non-epistemic explanations of the disagreement (e.g., generous funding by interested parties or particular policy preferences)? There are clearly rich opportunities for philosophical-psychological collaboration on such projects. Philosophical accounts of the normative appropriateness of steadfastness might be used to inform further psychological investigation to determine whether we may apply such norms in real world contexts.

It is also an open question at this point whether our results generalize to other cases. As discussed, we intentionally chose a case that showed little interaction with political or religious ideology in order to focus on the epistemic phenomena. This may provide insight into prospective 
use of denialist skeptical strategies but interactions with ideology will presumably complicate matters in cases about which there is already significant denialist noise. But how exactly this works and how it can be combated are important questions that deserve philosophers' and psychologists' attention.

\section{REFERENCES}

Ahola, Salla (2016) "Why (Not) Disagree? Human Values and the Readiness to Question Experts' Views," Public Understanding of Science 26(3): 339-354

Almassi, Ben (2012) “Climate Change, Epistemic Trust, and Expert Trustworthiness," Ethics \& the Environment 17 (2):29-49.

Anderson, Ashley A., Dominique Brossard, Dietram A. Scheufele, Michael A. Xenos, and Peter Ladwig (2014) "The "Nasty Effect:" Online Incivility and Risk Perceptions of Emerging Technologies," Journal of Computer-Mediated Communication 19 (3):373-387.

Anderson, Elizabeth (2011) "Democracy, Public Policy, and Lay Assessments of Scientific Testimony," Episteme 8 (2):144-164.

Austin, J.L. (1946/1979) “Other Minds", reprinted in his Philosophical Papers. Oxford: Oxford University Press.

Christensen, David (2007) "Epistemology of Disagreement: The Good News," Philosophical Review 116 (2):187-217.

Christensen, David (2014) “Disagreement and Public Controversy," in Jennifer Lackey (ed.), Essays in Collective Epistemology. New York: Oxford University Press.

Coady, David, and Richard Corry (2013) The Climate Change Debate: An Epistemic and Ethical Enquiry. Basingstoke: Palgrave Macmillan.

Cohen, Stanley (2001) States of Denial: Knowing About Atrocities and Suffering. Cambridge: Polity Publishers.

Collins, Harry, and Robert Evans (2007) Rethinking Expertise. Chicago: University of Chicago Press.

Diethelm, Pascal, and Martin McKee (2009) "Denialism: What Is It and How Should Scientists Respond?," European Journal of Public Health 19 (1):2-4.

Dunlap, Riley E., and Aaron M. McCright (2011) “Organized Climate Change Denial,” in John S. Dryzek, Richard B. Norgaard and David Schlosberg (eds.), The Oxford Handbook of Climate Change and Society. Oxford: Oxford University Press.

Fogelin, Robert J. (1994) Pyrrhonian Reflections on Knowledge and Justification. New York: Oxford University Press.

Garvey, James (2008) The Ethics of Climate Change: Right and Wrong in a Warming World. London: Continuum Publishers.

Goldman, Alvin (2001) “Experts: Which Ones Should You Trust?,” Philosophy and Phenomenological Research LXIII (1):85-110.

HORP (2016) "Public Views of the Zika Virus Outbreak Topline Data", in, Harvard T. H. Chan School of Public Health: Harvard Opinion Research Program

IPCC (2014) Climate Change 2014: Synthesis Report. Contribution of Working Groups I, II and III to the Fifth Assessment Report of the Intergovernmental Panel on Climate Change. Geneva: IPCC.

Kahan, Dan M. (2014) "Making Climate-Science Communication Evidence-Based — All the Way Down," in Deserai A. Crow and Maxwell T. Boykoff (eds.), Culture, Politics and Climate Change: How Information Shapes our Common Future. Abingdon: Routledge, 203-220. 
Kahan, Dan M., Hank Jenkins-Smith, and Donald Braman (2011) "Cultural Cognition of Scientific Consensus," Journal of Risk Research 14 (2):147-174.

Kalichman, Seth C. (2009) Denying AIDS: Conspiracy Theories, Pseudoscience, and Human Tragedy. New York: Copernicus Books.

Kelly, Thomas (2010) "Peer Disagreement and Higher-Order Evidence", in Feldman and Warfield 2010: 111-174.," in Richard Feldman and Ted A. Warfield (eds.), Disagreement. Oxford: Oxford University Press.

Keren, Arnon (2007) “Epistemic Authority, Testimony and the Transmission of Knowledge," Episteme 4 (3):368-381.

Kuhn, Joseph (2012) "Passive Smoking and "Denialism": Motives and Strategies of Denial of Scientific Evidence," Prävention 35:11-14.

Lackey, Jennifer (2010) “A Justificationist View of Disagreement's Epistemic Significance,” in Adrian Haddock, Alan Millar and Duncan Pritchard (eds.), Social Epistemology. Oxford: Oxford University press.

Leiserowitz, Anthony A., Edward W. Maibach, Connie Roser-Renouf, Nicholas Smith, and Erica Dawson (2013) "Climategate, Public Opinion, and the Loss of Trust," American Behavioral Scientist 57 (6):818837.

Lewandowsky, Stephan, Michael E. Mann, Nicholas J.L. Brown, and Harris Friedman (2016) "Science and the Public: Debate, Denial, and Skepticism," Journal of Social and Political Psychology 4 (2):537-553.

Lipton, Peter (1998) "The Epistemology of Testimony," Studies in the History and Philosophy of Science 29 (1):1-31.

Markowitz, Ezra M., and Azim F. Shariff (2012) "Climate Change and Moral Judgement," Nature Climate Change 2:243-247.

McCright, Aaron M., Meghan Charters, Katherine Dentzman, and Thomas Dietz (2016) "Examining the Effectiveness of Climate Change Frames in the Face of a Climate Change Denial Counter-Frame," Topics in Cognitive Science 8:76-97.

Merton, Robert K (1942) “The Normative Structure of Science”, reprinted in his The Sociology of Science: Theoretical and Empirical Investigations. Chicago: University of Chicago Press.

Michaels, David (2008) Doubt Is Their Product: How Industry's Assault on Science Threatens Your Health. Oxford: Oxford University Press.

Moore, G.E. (1925/1993) “A Defence of Common Sense," in T. Baldwin (ed.), G. E. Moore: Selected Writings. London: Routledge.

Moore, G.E. (1939/1993) "Proof of an External World," in T. Baldwin (ed.), G. E. Moore: Selected Writings. London: Routledge.

Norgaard, Kari Marie (2011) Living in Denial: Climate Change, Emotions, and Everyday Life. Cambridge, MA: The MIT Press.

Odenbaugh, Jay (2012) "Climate, Consensus, and Contrarians," in William P. Kabasenche, Michael O'Rourke and Matthew H. Slater (eds.), The Environment: Philosophy, Science, and Ethics. Cambridge: MIT Press.

Oreskes, Naomi, and Erik M. Conway (2010a) Merchants of Doubt. New York: Bloomsbury Press.

Oreskes, Naomi, and Erik M. Conway (2010b) “Defeating the Merchants of Doubt," Nature 465:686-687.

Sextus Empiricus (2000) Outlines of Scepticism. Translated by Julia Annas and Jonathan Barnes. Cambridge: Cambridge University Press. 
Steffen, Will (2011) "A Truly Complex and Diabolical Policy Problem," in John S. Dryzek, Richard B. Norgaard and David Schlosberg (eds.), The Oxford Handbook of Climate Change and Society. Oxford: Oxford University Press.

Torcello, Lawrence (2016) “The Ethics of Belief, Cognition, and Climate Change Pseudoskepticism: Implications for Public Discourse," Topics in Cognitive Science 8:19-48.

van der Linden, Sander L., Anthony Leiserowitz, Seth Rosenthal, and Edward Maibach (2017) "Inoculating the Public against Misinformation about Climate Change," Global Challenges 1(2): 1600008. 


\section{Denialism as Applied Skepticism Supporting Material}

\section{Treatment: Zika Expository paragraph}

Scientists studying the recent Zika virus epidemic in South and North America agree that the Zika virus is spread through the bites of the Aedes aegypti mosquito and via sexual transmission. Zika infection generally causes mild symptoms such as fever, rash, joint pain, and conjunctivitis (red eyes). But the main risk associated with Zika is infection in pregnant women. Zika can cause severe birth defects such as microcephaly, a condition in which babies are born with abnormally small heads and underdeveloped brains, leading to lifelong problems such as seizures, developmental delays, or even death. While scientists are presently working on a vaccine for Zika, none currently exists.

\section{Study 1 Demographic Information}

Gender

What is your gender identity?

$\begin{array}{lll} & \text { Frequency } & \text { Percent } \\ \text { Male } & 367 & 48.4 \\ \text { Female } & 381 & 50.3 \\ \text { Transgender } & 3 & .4 \\ \text { Another identity } & 3 & .4 \\ \text { I prefer not to respond } & 3 & .4 \\ \text { Total } & 757 & 99.9 \\ \text { Missing } & 1 & .1 \\ \text { Total } & 758 & 100.0\end{array}$

\section{Political Party}

"Generally speaking, do you usually think of yourself as a Republican, a Democrat, an Independent,..."

$\begin{array}{lll} & \text { Frequency } & \text { Percent } \\ \text { Republican } & 184 & 24.3 \\ \text { Democrat } & 317 & 41.8 \\ \text { Independent } & 217 & 28.6 \\ \text { Other } & 14 & 1.8 \\ \text { No preference } & 24 & 3.2 \\ \text { Total } & 756 & 99.7 \\ \text { Missing } & 2 & .3 \\ \text { Total } & 758 & 100.0\end{array}$




\section{Income}

"Information about income is very important to understand. Would you please give your best guess?...."

$\begin{array}{lll}\text { Less than } \$ 10,000 & 48 & 6.3 \\ \$ 10,000 \text { to } \$ 19,999 & 67 & 8.8 \\ \$ 20,000 \text { to } \$ 29,999 & 111 & 14.6 \\ \$ 30,000 \text { to } \$ 39,999 & 80 & 10.6 \\ \$ 40,000 \text { to } \$ 49,999 & 75 & 9.9 \\ \$ 50,000 \text { to } \$ 59,999 & 82 & 10.8 \\ \$ 60,000 \text { to } \$ 69,999 & 64 & 8.4 \\ \$ 70,000 \text { to } \$ 79,999 & 66 & 8.7 \\ \$ 80,000 \text { to } \$ 89,999 & 42 & 5.5 \\ \$ 90,000 \text { to } \$ 99,999 & 35 & 4.6 \\ \$ 100,000 \text { to } \$ 149,999 & 62 & 8.2 \\ \$ 150,000 \text { or more } & 24 & 3.2 \\ \text { Total } & 756 & 9.7 \\ \text { Missing } & 2 & .3 \\ \text { Total } & 758 & 100.0\end{array}$

\section{Education}

"What is the highest level of school you have completed or the highest degree you have received?"

Less than high school degree

High school graduate (high school diploma or equivalent including GED)

Some college but no degree

Associate degree in college (2-year)

Bachelor's degree in college (4-year)

Master's degree

Doctoral degree

Professional degree (JD, MD)

Total
Frequency Percent

4

.5

75

196

9.9

107

25.9

280

14.1

67

36.9

13

8.8

$16 \quad 2.1$

$758 \quad 100.0$ 
Race

"Choose one or more race you consider yourself to be:"

White

Black or African American

Frequency Percent

American Indian or Alaskan Native

$631 \quad 83.2$

Asian

$54 \quad .07$

Native Hawaiian or Pacific Islander

$9 \quad .01$

Other

$61 \quad .08$

$0 \quad .00$

$20 \quad .03$

(total is greater than 1802 because respondents could select multiple choices.)

\section{Study 2 Demographic Information}

\section{Gender}

"What is your gender identity?"

$\begin{array}{lll} & \text { Frequency } & \text { Percent } \\ \text { Male } & 759 & 42.1 \\ \text { Female } & 1031 & 57.2 \\ \text { Transgender } & 2 & .1 \\ \text { Another identity } & 1 & .1 \\ \text { I prefer not to respond } & 7 & .4 \\ \text { Total } & 1800 & 99.9 \\ \text { Missing } & 2 & .1 \\ \text { Total } & 1802 & 100.0\end{array}$

Political Party

"Generally speaking, do you usually think of yourself as a Republican, a Democrat, an Independent,..."

$\begin{array}{lll} & \text { Frequency } & \text { Percent } \\ \text { Republican } & 542 & 30.1 \\ \text { Democrat } & 617 & 34.2 \\ \text { Independent } & 505 & 28.0 \\ \text { Other } & 25 & 1.4 \\ \text { No preference } & 100 & 5.5 \\ \text { Total } & 1789 & 99.3 \\ \text { Missing } & 13 & .7 \\ \text { Total } & 1802 & 100.0\end{array}$




\section{Income}

"Information about income is very important to understand. Would you please give your best guess?..."

$\begin{array}{lll}\text { Less than } \$ 10,000 & 44 & 2.4 \\ \$ 10,000 \text { to } \$ 19,999 & 79 & 4.4 \\ \$ 20,000 \text { to } \$ 29,999 & 116 & 6.4 \\ \$ 30,000 \text { to } \$ 39,999 & 152 & 8.4 \\ \$ 40,000 \text { to } \$ 49,999 & 180 & 10.0 \\ \$ 50,000 \text { to } \$ 59,999 & 177 & 9.8 \\ \$ 60,000 \text { to } \$ 69,999 & 183 & 10.2 \\ \$ 70,000 \text { to } \$ 79,999 & 153 & 8.5 \\ \$ 80,000 \text { to } \$ 89,999 & 88 & 4.9 \\ \$ 90,000 \text { to } \$ 99,999 & 97 & 5.4 \\ \$ 100,000 \text { to } \$ 149,999 & 305 & 16.9 \\ \$ 150,000 \text { or more } & 225 & 12.5 \\ \text { Total } & 1799 & 99.8 \\ \text { Missing } & 3 & .2 \\ \text { Total } & 1802 & 100.0\end{array}$

\section{Education}

"What is the highest level of school you have completed or the highest degree you have received?"

Less than high school degree

High school graduate (high school diploma or equivalent including GED)

Some college but no degree

Associate degree in college (2-year)

Bachelor's degree in college (4-year)

Master's degree

Doctoral degree

Professional degree (JD, MD)

Total

Missing

Total

$\begin{array}{ll}\text { Frequency } & \text { Percent } \\ 13 & .7 \\ & \\ 238 & 13.2 \\ 389 & 21.6 \\ 232 & 12.9 \\ 532 & 29.5 \\ 313 & 17.4 \\ 30 & 1.7 \\ 54 & 3.0 \\ 1801 & 99.9 \\ 1 & .1 \\ 1802 & 100.0\end{array}$


Race

"Choose one or more race you consider yourself to be:"

White

Black or African American

American Indian or Alaskan Native

Asian

Native Hawaiian or Pacific Islander

Other

$\begin{array}{ll}\text { Frequency } & \text { Percent } \\ 1575 & 87.4 \\ 87 & 4.8 \\ 25 & 1.4 \\ 87 & 4.8 \\ 6 & .30 \\ 46 & 2.6\end{array}$

(total is greater than 1802 because respondents could select multiple choices.) 
Table 3: Mean and Standard Deviation for belief change by Statement Set (negative values represent decreases from pre-belief to post-belief). ${ }^{*}=$ mean is significantly different from the control at the .001 level; Dose 3 sets exhibiting internal conflict indicated with '\#’.

\begin{tabular}{|c|c|c|c|c|}
\hline & Statement Sets & $\mathrm{N}$ & Mean & Std. Deviation \\
\hline & Control & 184 & .32 & 31.49 \\
\hline \multirow[t]{6}{*}{ Dose 1 Sets } & S1 & 143 & $-15.80^{*}$ & 45.98 \\
\hline & S2 & 137 & 1.56 & 25.27 \\
\hline & S3 & 130 & -6.71 & 32.42 \\
\hline & G1 & 137 & -6.93 & 39.42 \\
\hline & G2 & 135 & .71 & 20.57 \\
\hline & G3 & 137 & -10.69 & 34.35 \\
\hline \multirow[t]{20}{*}{ Dose 3 Sets } & S1,S2,G1 & 48 & -8.50 & 37.35 \\
\hline & $\mathrm{S} 1, \mathrm{~S} 2, \mathrm{~S} 3$ & 41 & -23.22 & 57.10 \\
\hline & $\mathrm{S} 1, \mathrm{~S} 3, \mathrm{G} 1$ & 42 & -19.64 & 61.34 \\
\hline & $S 1, S 2, G 2 \#$ & 35 & -2.43 & 39.96 \\
\hline & $\mathrm{S} 1, \mathrm{~S} 3, \mathrm{G} 1$ & 48 & -18.13 & 59.47 \\
\hline & $\mathrm{S} 1, \mathrm{~S} 3, \mathrm{G} 2$ & 34 & -13.26 & 40.19 \\
\hline & $S 1, S 2, G 3 \#$ & 37 & -14.27 & 36.09 \\
\hline & $S 2, S 3, G 2 \#$ & 38 & -6.08 & 31.37 \\
\hline & S1,S3,G3 & 49 & -17.10 & 40.14 \\
\hline & S1,G1,G2 & 52 & -14.79 & 53.13 \\
\hline & $S 2, S 3, G 3 \#$ & 34 & -6.68 & 44.56 \\
\hline & $S 2, G 1, G 2 \#$ & 38 & -1.63 & 26.63 \\
\hline & S1,G1,G3 & 36 & -7.61 & 31.64 \\
\hline & S3,G1,G2 & 39 & -18.36 & 41.46 \\
\hline & $S 2, G 1, G 3 \#$ & 40 & 5.28 & 28.51 \\
\hline & S1,G2,G3 & 34 & -7.32 & 27.93 \\
\hline & S3,G1,G3 & 49 & $-28.63^{*}$ & 65.48 \\
\hline & $S 2, G 2, G 3 \#$ & 30 & .73 & 32.59 \\
\hline & S3,G2,G3 & 36 & -10.22 & 26.64 \\
\hline & G1,G2,G3 & 39 & -3.03 & 17.00 \\
\hline
\end{tabular}


